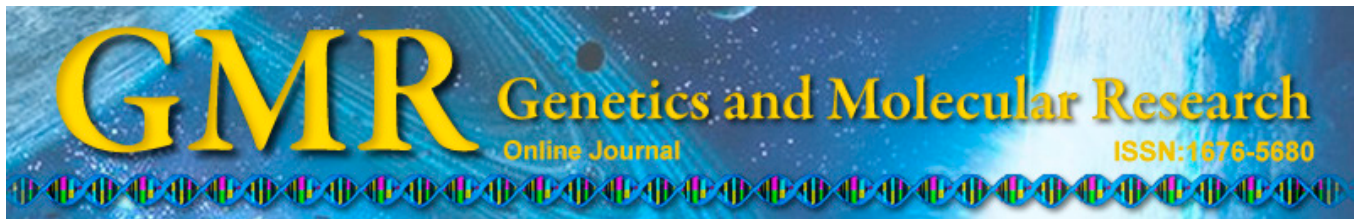

\title{
Analysis of microbial diversity and niche in rhizosphere soil of healthy and diseased cotton at the flowering stage in southern Xinjiang
}

\author{
F.G. Luan ${ }^{1,3}$, L.L. Zhang ${ }^{3}$, Y.Y. Lou ${ }^{3}$, L. Wang ${ }^{3}$, Y.N. Liu ${ }^{3}$ and H.Y. Zhang ${ }^{2,3}$ \\ ${ }^{1}$ College of Landscape and Art, Jiangxi Agriculture University, Nanchang, \\ Jiangxi, China \\ ${ }^{2}$ Water and Ecological Engineering, Nanchang Institute of Technology, \\ Nanchang, Jiangxi, China \\ ${ }^{3}$ Key Laboratory of Protection and Utilization of Biological Resources in \\ Tarim Basin, Xinjiang Production and Construction Corps, Alar, Xinjiang, \\ China
}

Corresponding author: H.Y. Zhang

E-mail: zhanghaiyansw03@163.com

Genet. Mol. Res. 14 (1): 1602-1611 (2015)

Received January 16, 2014

Accepted December 12, 2014

Published March 6, 2015

DOI http://dx.doi.org/10.4238/2015.March.6.7

\begin{abstract}
Understanding how microbial community composition and diversity respond to continuous cropping obstacle is not well understood. However, determining the community composition vs assessing the diversity of molecular operational taxonomic units is often difficult. In this study, we focused on the microbial diversity and niche differentiation in rhizosphere soils between healthy and diseased cotton using a molecular approach based on a culture-independent method. A total of 124 operational taxonomic units (OTUs) from 1076 DNA fragments were detected, including 46, 57, and 21 OTUs from fungi, bacteria, and actinomycetes, respectively. The identified OTUs were confirmed by sequencing after polymerase chain reaction-restriction
\end{abstract}


fragment length polymorphism analysis. The number of OTUs from Fusarium species in diseased rhizosphere soils was higher than that in healthy rhizosphere, which was consistent with field observations. Overall, the results showed that microbes in healthy rhizosphere soils were more diverse and occupied a wider niche in the healthy rhizosphere soil environment of the cotton field. Beneficial microbes should further be analyzed in studies examining the soil ecology of fields in which continuous cropping of cotton takes place.

Key words: Cotton; Continuous cropping; Culture-independent methods; Microbial communities

\section{INTRODUCTION}

Cotton is a pillar industry for the economic development of southern Xinjiang, China. However, limitations to production arise as continuous cropping years increase, such as maladjusted soil nutrients, imbalance of soil ecology, serious pests and diseases, and decrease in cotton yield and quality. The soil microbial community in cotton changes continuously with the fast expansion of planting areas and with repeated tillage, which is useful for modeling nutrient and energy cycling (Stockdale and Brookes, 2006). Previous studies on continuous cropping limitations in China have primarily focused on greenhouse vegetables (Hu et al., 2007), soybean (Li et al., 2006), and Chinese herbal medicine (Zhang et al., 2005), whereas few studies have been conducted to examine cotton (Zhang et al., 2011).

The rhizosphere encompasses a few millimeters of soil surrounding the plant root, an area where multifaceted ecological and biological processes take place (Kennedy, 1998). The rhizosphere has long been considered to be the natural reservoir for microorganisms. A large array of microbes can inhabit the rhizosphere, and it is widely accepted that members from all microbial groups perform important functions in the rhizosphere (Giri et al., 2005). Because of the secluded nature of the rhizosphere, it has not been thoroughly examined. However, there have been significant discoveries, particularly regarding the biological control of root pathogens (Whipps, 2001) and phytoremediation (Pilon-Smits, 2005). Costa et al. (2006) found that the microbial community varies in composition in rhizosphere and nonrhizosphere soil, as well as in different plants. The composition and species soil microbes were more simple in the rhizosphere compared to the nonrhizosphere, primarily because of the selectivity of roots (Costa et al., 2006). An increased understanding of rhizosphere microorganism ecology will not only facilitate the development of successful microbial control strategies against soilborne disease, but also contribute to the knowledge of subterranean microbial ecology.

Previously, microbial analysis in environmental samples depended on traditional culture methods. However, only $0.1-1 \%$ microbe can be recovered using these techniques (Amann et al., 1995). Molecular techniques, particularly polymerase chain reaction (PCR) (Mullis et al., 1994), have revolutionized microbiology studies, including the study of soil microbiology. Molecular techniques enable the differentiation of microbial species and varieties. Metagenomics allows the direct study of communities of microbial organisms in their natural environments, bypassing the need for isolation and lab cultivation of individual species (DeLong, 2002). This has enabled the study of uncultivable microorganisms by genome sequencing; furthermore, it provides system-level insights into the composition, structure, and 
functioning of microbial communities from various environments (Warnecke et al., 2007).

Culture-independent methodologies such as environmental metagenomics are applied for studying communities of microbial organisms in situ, bypassing the need for isolation and lab cultivation of individual species (DeLong, 2002). Culture-independent retrieval of 16S rRNA genes was pioneered by Olsen et al. (1986) 2 decades ago. Since then, the cultureindependent molecular techniques have been used to study bacterial communities (Huang et al., 2006). Moreover, metagenomics has revolutionized microbiology as approximately $99 \%$ of microbial species cannot be cultivated (Hugenholtz, 2002).

Advances in most DNA-based analysis techniques allow samples to be simultaneously screened for a large number of microbes. Fingerprinting analysis of microbial communities can be carried out using denaturing gradient gel electrophoresis (Kowalchuk et al., 1997), temperature gradient gel electrophoresis (Fouratt et al., 2003), terminal-restriction fragment length polymorphism (RFLP) (Mintie et al., 2003), and single-strand conformation polymorphism (Bäckman et al., 2003). Molecular (i.e., culture-independent) methods, particularly those based on the 16S rRNA gene, are very important in modern microbial ecology (Tringe and Hugenholtz, 2008).

Functional genes are frequently used in RFLP analysis for identifying specific microbial groups in complex environments, which can be affected by a number of underlying factors (Sipos et al., 2007). Zhang et al. (2011) detected bacterial communities in rhizosphere soils of healthy and diseased cotton responsive to terminal RFLP and 16S rDNA clone libraries. The highest richness of soil samples from the rhizosphere between healthy and diseased differed at various plant growth stages. Acidobacteria and Proteobacteria were found to be the most prevalent phyla in the cotton rhizosphere (Zhang et al., 2011).

In this study, we examined whether an association exists between healthy and diseased cotton and species of microbes using RFLP and sequencing methods to determine the composition and diversity of naturally occurring microbes in the rhizosphere of cotton grown in the oasis farmland of southern Xinjiang. The results were compared to the ecological niche of rhizosphere microbes using cultivation-dependent methods, enabling highly reliable and rapid detection and quantification of microbes associated with healthy and diseased cotton. Our results will facilitate environmental surveys of targeted microbes and the identification of environmental factors influencing their distribution.

\section{MATERIAL AND METHODS}

\section{Study area and sampling procedure}

This study was conducted at the Regimental Farm No. 3, Agricultural Division No. 1, at the Xinjiang Production and Construction Corps, China. The study area is the main cottonproducing region near $40.375^{\circ} \mathrm{N}$ and $80.136^{\circ} \mathrm{S}$ latitude that had been continuously cropped for 15 years and belonging to the typical desert oasis with typical continental and arid climate (Zheng and Yu, 1996). The plant variety examined was hybrid cotton Xinluzhong 41. Based on the symptoms of Fusarium wilt in cotton, diseased and healthy cotton plants were selected. Soil samples were collected from rhizosphere soils of cotton during the boll-opening period. After surface soil (approximately 1-2 cm) was removed, soil attached to the roots was used as the rhizosphere soil samples. All samples were preserved at $4^{\circ} \mathrm{C}$ until isolation of soil fungi. 


\section{Extraction of soil DNA}

DNA extraction from rhizosphere soil samples was performed using the method of Zhou et al. (1996), with some modifications. A $0.5 \mathrm{~g}$ soil sample was mixed with $1.3 \mathrm{~mL}$ DNA extraction buffer (100 mM Tris-HCl, $\mathrm{pH} 8.0,100 \mathrm{mM}$ sodium EDTA, $\mathrm{pH}$ 8.0, $100 \mathrm{mM}$ sodium phosphate, $\mathrm{pH} 8.0,1.5 \mathrm{M} \mathrm{NaCl}$, and $1 \%$ cetrimonium bromide). After vortexing, the mixture was placed in liquid nitrogen for $5 \mathrm{~min}$, followed by incubation at $65^{\circ} \mathrm{C}$ to melt the sample. This process was repeated 3 times. Next, $100 \mu \mathrm{L} 10 \mathrm{mg} / \mathrm{mL}$ proteinase $\mathrm{K}$ was added and the tubes were then shaken horizontally at $250 \mathrm{rpm}$ for $30 \mathrm{~min}$ at $37^{\circ} \mathrm{C}$. After shaking, $200 \mu \mathrm{L} 20 \%$ sodium dodecyl sulfate was added, and the tubes were incubated in a water bath at $65^{\circ} \mathrm{C}$ for $2 \mathrm{~h}$ with gentle end-over-end inversions every 15-20 min. After cooling to room temperature, the tubes were centrifuged at $6000 \mathrm{rpm}$ for $10 \mathrm{~min}$ at room temperature and the supernatants were transferred to clean $2-\mathrm{mL}$ centrifuge tubes. The soil pellets were extracted by adding $750 \mu \mathrm{L}$ extraction buffer and $50 \mu \mathrm{L} 20 \%$ sodium dodecyl sulfate; the samples were vortexed for $10 \mathrm{~s}$, incubated at $65^{\circ} \mathrm{C}$ for $10 \mathrm{~min}$, and centrifuged as described above. The lysates from the 2 extraction cycles was combined and mixed with 0.5 -fold volume of polyethylene glycol $8000(50 \% \mathrm{w} / \mathrm{v}, 1.5 \mathrm{M} \mathrm{NaCl})$. The tubes were homogenized mixing and incubated overnight. The tubes were centrifuged at $6000 \mathrm{rpm}$ for $10 \mathrm{~min}$ at room temperature and the supernatants were discarded. The pellet was dissolved in $500 \mu \mathrm{L} 1 \mathrm{X}$ TE buffer ( $10 \mathrm{mM}$ Tris-HCl, $1 \mathrm{mM}$ EDTA) and added an equal time volume of phenol-chloroform-isoamyl alcohol (25:24:1). The tubes were centrifuged at 12,000 rpm for $10 \mathrm{~min}$ at room temperature and the supernatant was extracted using an equal volume of phenol-chloroform-isoamyl alcohol $(25: 24: 1)$. The aqueous phase was precipitated with 0.6 times the volume of isopropanol and 0.1 times the volume of isopropanol at $-20^{\circ} \mathrm{C}$ overnight. The nucleic acid pellet was centrifuged at $12,000 \mathrm{rpm}$ for $10 \mathrm{~min}$ at room temperature. The crude extracts were washed with $70 \%$ cold ethanol, resuspended in $50 \mu \mathrm{L}$ ultrapure water (shown in Figure 1A), and stored at $-20^{\circ} \mathrm{C}$. DNA was purified using the Agarose Gel DNA Purification Kit Ver. 2.0 (Takara, Shiga, Japan) according to manufacturer instructions.

\section{PCR amplification, cloning, and enzyme digestion}

Primers were synthesized by Biosune (Shanghai, China). Primers used for PCR were ITS4 (5'-TCCTCCGCTTATTGATATGC-3') and ITS5 (5'-GGAAGTAAAAGTCGTAACAAGG-3') for fungi (White et al., 1990). Amplification conditions were as follows: 2 min at $94^{\circ} \mathrm{C}$, followed by 35 cycles for $30 \mathrm{~s}$ at $94^{\circ} \mathrm{C}, 30 \mathrm{~s}$ at $52^{\circ} \mathrm{C}, 1 \mathrm{~min}$ at $72^{\circ} \mathrm{C}$, and a final step for $10 \mathrm{~min}$ at $72^{\circ} \mathrm{C}$.

Primers used for PCR were F243 (5'-GGATGAGCCCGCGGCCTA-3') and R1378 (5'-CGGTGTGTACAAGGCCCGGGAACG-3') for bacteria (Heuer et al., 1997) (shown in Figure 1B). Thermal cycling was initiated at $94^{\circ} \mathrm{C}$ for $3 \mathrm{~min}$, followed by 35 cycles for $1 \mathrm{~min}$ at $94^{\circ} \mathrm{C}, 1 \mathrm{~min}$ at $55^{\circ} \mathrm{C}, 1 \mathrm{~min}$ at $72^{\circ} \mathrm{C}$, and a final step for $7 \mathrm{~min}$ at $72^{\circ} \mathrm{C}$.

Primers used for PCR were S20 (5'-CGCGGCCTATCAGCTTGTTG-3') and A19 (5'-CCGTACTCCCCAGGCGGGG-3') for actinomycetes (Stach et al., 2003) (shown in Figure 1C). Amplification conditions were as follows: 4 min at $94^{\circ} \mathrm{C}$ followed by 35 cycles for 45 s at $94^{\circ} \mathrm{C}, 1 \mathrm{~min}$ at $68^{\circ} \mathrm{C}, 1 \mathrm{~min}$ at $72^{\circ} \mathrm{C}$, and a final step for $8 \mathrm{~min}$ at $72^{\circ} \mathrm{C}$.

PCRs for the 3 genes were prepared in $25 \mu \mathrm{L}$ solution containing 1X PCR buffer, $2 \mathrm{mM}$ $\mathrm{MgSO}_{4}, 0.2 \mathrm{mM}$ dNTPs, $0.2 \mu \mathrm{M}$ of each forward and reverse primers, 1 U Taq DNA polymerase (Dream Taq ${ }^{\mathrm{TM}}$, Fermentas Life Science, Vilnius, Lithuania), and 5-10 ng template DNA. 


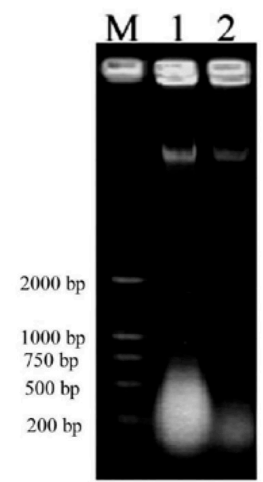

A

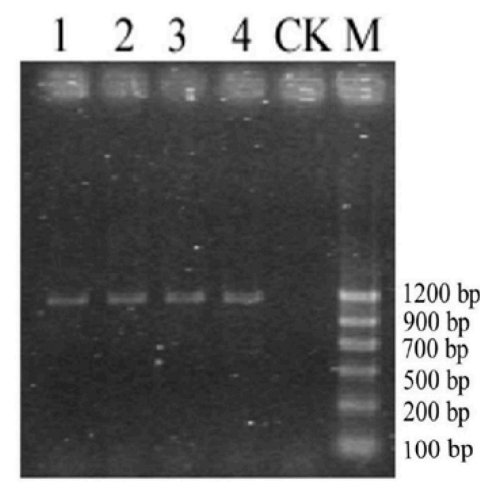

B

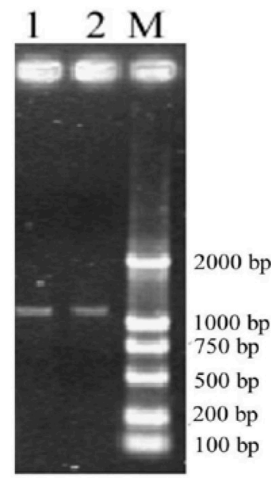

$\mathrm{C}$

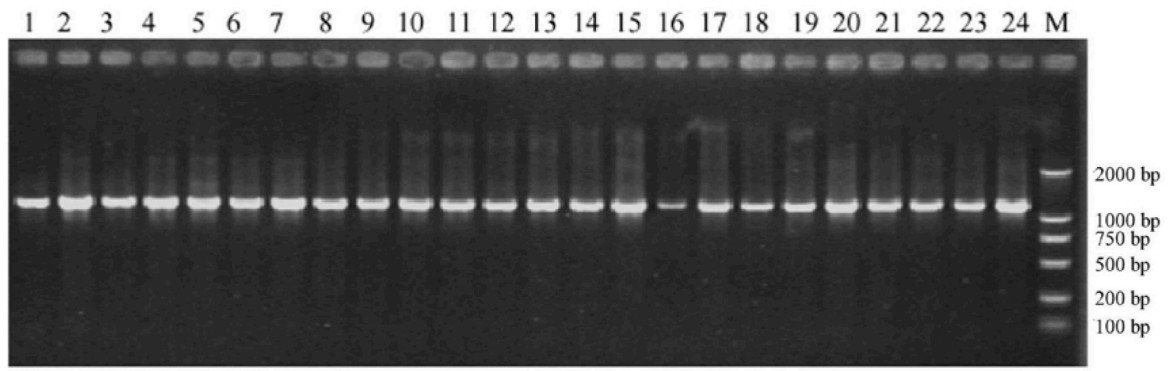

D

Figure 1. Monitoring actinobacterial composition. A. Agarose gel electrophoresis of total DNA extracted from soil. B. Agarose gel electrophoresis of 16S rDNA amplification products from DNA of soil samples for actinomycetes. C. Agarose gel electrophoresis detection for recovery of PCR products of actinobacteria. D. Clonal expansion of 16S rDNA for actinomycetes. Marker of DL2000 in A, C and D, while DL1200 in B.

\section{DNA purification and PCR for RFLP}

PCR amplicons were separated on a $2.5 \%$ agarose gel and stained with ethidium bromide. The prominent bands were excised from the gel and DNA was eluted using the SanPrep Column DNA Gel Extraction Kit (Sangon, Shanghai, China). Amplicons were cloned into the pMD18-T vector using a PCR Cloning Kit (Takara) according to manufacturer instruction. After transformation of the recombinant vectors into Escherichia coli strain DH5 $\alpha$, transformants were screened by blue-white selection on LB agar plates containing $100 \mu \mathrm{g} / \mathrm{mL}$ ampicillin. White colonies were then transferred to fresh plates and incubated overnight. Screening was performed by PCR with the M13F (5'-CAGGAAACAGCTATGAC-3') and M13R (5'-GTAAAACGACGGCCAGT-3') primers. Clones with inserts were identified based on amplicon size. All of the above protocols in this study were described by Sambrook et al. (2001).

In experiments involving large numbers of clones with inserts of similar lengths, the colonies were screened for diversity by PCR-RFLP as described previously (Brežná et al., 2010). HaeIII was selected as the optimal enzyme for fungi, bacteria, and actinomycetes. Isolates for which identical RFLP patterns were considered to belong to the same RFLP group were selected for sequencing. Nucleotide sequencing of PCR products was performed by 
Shanghai Invitrogen Biotechnology Co., Ltd. (Shanghai, China).

\section{Data analysis}

The values of estimated sample coverage $(C)$, estimated sample coverage for rare species ( $C_{-}$rare), and estimated $C V$ for rare species ( $C V$ rare) for each of the clone libraries were calculated using the Species Prediction and Diversity Estimation software (Chao and Shen, 2008).

The value of Shannon index $\left(H_{\mathrm{S}}\right)$, species evenness $(\mathrm{E})$, Simpson index (D), niche breadth (M), niche overlap index $(\mathrm{H})$, and Jaccard (1901) dissimilarity coefficient (J) were analyzed using SPSS version 15.0 (SPSS Inc., Chicago, IL, USA) with guidance (Pallant, 2007). Nucleotide sequences for the isolates were searched for their similarity index using the BLAST software (http://blast.ncbi.nlm.nih.gov/Blast.cgi).

\section{Nucleotide sequence accession numbers}

Internal transcribed spacer rRNA gene sequence data for uncultured fungi were deposited in the GenBank database under accession Nos. KC191742, KC191744-KC191748, KC191750-KC191753, and KC191760-KC191762; 16S rRNA gene sequence data for uncultured bacteria were KC191741, KC191755, and KC191764-KC191774. The 16S rRNA gene sequence data for uncultured actinomycetes were KC191784-KC191785, KC191788, and KC191791-KC191792.

\section{RESULTS}

\section{Construction of clone libraries}

PCR amplification resulted in single products of approximately 600, 1500, and 1260 bp for fungal, bacterial (data not shown), and actinomycetic clones (Figure 1D). Moreover, the combination rates from clone fungi, bacteria, and actinomycetes were 74.08, 73.04, and $66.14 \%$, respectively (Figure 2).

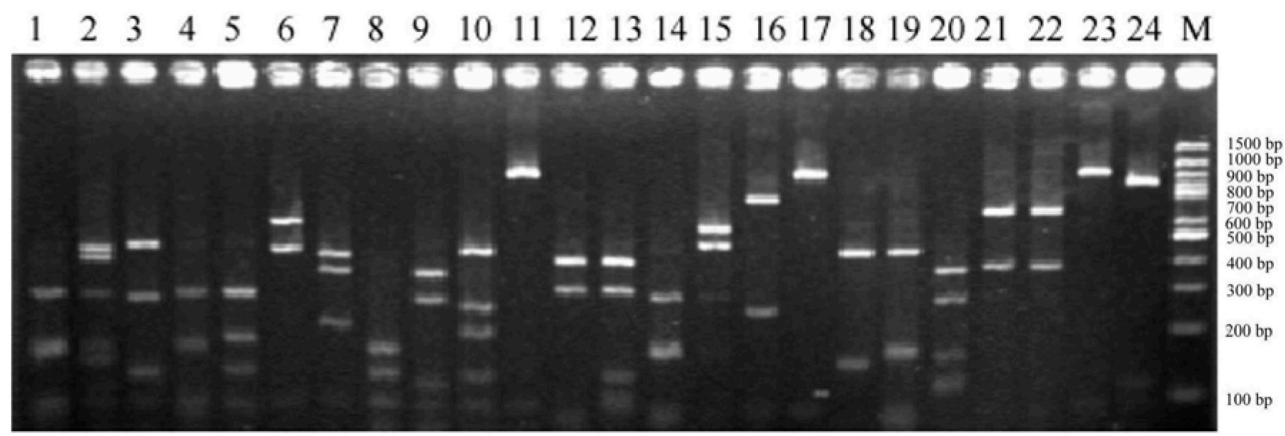

Figure 2. RFLP patterns of the $16 \mathrm{~S}$ rDNA region amplified from the clones of actinobateria and digested with the endonuclease of HinfI. OTU1 = lanes 1, 4, 14; OTU2 = lane 2; OTU3 = lane 3; OTU4=lane 5; OTU5 = lane 6; OTU6 = lane 7; OTU7 = lane 8; OTU8 = lane 9; OTU9 = lane 10; OTU10 = lanes 11, 17, 23; OTU11 = lane 12; OTU12 = lane 13; OTU13 = lane 15; OTU14 = lane 16; OTU15 = lane 18; OTU16 = lane 19; OTU17 = lane 20; OTU18=lanes 21, 22; OTU19= lane 24; lane $M=100$-bp ladder. 


\section{Comparison of microorganism composition}

A total of 124 operational taxonomic units (OTUs) from 1076 DNA fragments were screened, including 46, 57, and 21 OTUs for fungi (Figure 3A), bacteria (Figure 3B), and actinomycetes (shown in Figure 3C), respectively. The percentages of overlapping OTUs from rhizosphere soil samples between healthy and diseased were $67.39 \%$ (31/46), 28.07\% (16/57), and $28.57 \%$ (6/21) for fungi, bacteria, and actinomycetes. Microbial diversity values, including $H_{\mathrm{s}}, \mathrm{E}$, and $\mathrm{D}$ in the rhizosphere soil of healthy cotton, were higher than in diseased plants. Furthermore, the niche breadths in healthy plants were higher than in diseased rhizosphere, and the niche overlap index and $\mathrm{J}$ discrepancy coefficient were low (0.5427-0.6729) (Table 1).
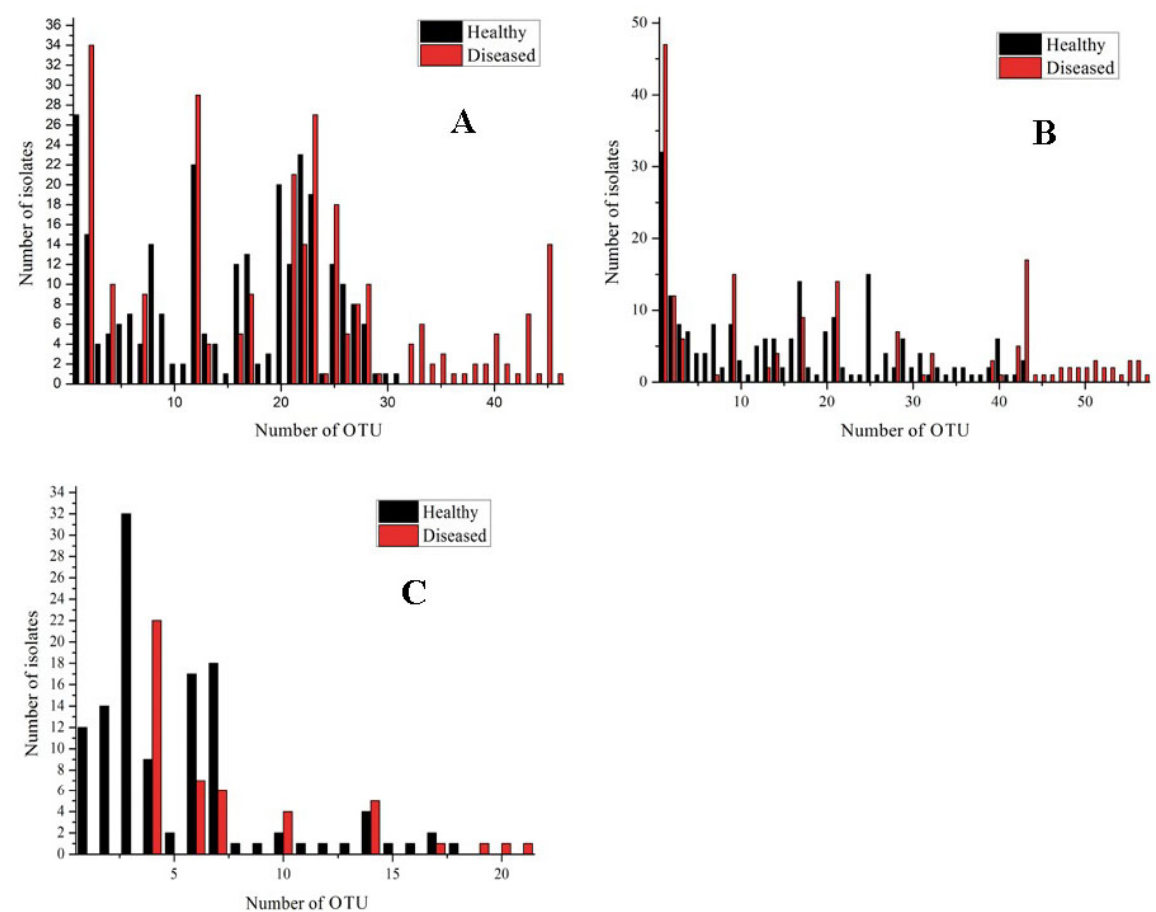

Figure 3. Distribution of operational taxonomic units (OTUs) in different clone libraries for fragments amplified from genomic DNA in rhizosphere soils of healthy and diseased cotton. A. Fungi. B. Bacteria. C. Actinomycetes. OUT was delineated at $80 \%$ phenotypic similarity level.

Table 1. Diversity calculated from RFLP microbial community fingerprints in the rhizosphere soils of healthy and diseased cotton.

\begin{tabular}{|c|c|c|c|c|c|c|}
\hline \multirow[t]{2}{*}{ Assemblage } & \multicolumn{2}{|c|}{ Fungi } & \multicolumn{2}{|c|}{ Bacteria } & \multicolumn{2}{|c|}{ Actinomycetes } \\
\hline & $\mathrm{H}$ & $\mathrm{D}$ & $\mathrm{H}$ & $\mathrm{D}$ & $\mathrm{H}$ & $\mathrm{D}$ \\
\hline$\overline{H_{\mathrm{S}}}$ & 4.457 & 4.261 & 4.790 & 3.938 & 3.212 & 2.400 \\
\hline$E^{s}$ & 0.8997 & 0.8601 & 0.8827 & 0.8026 & 0.7703 & 0.7571 \\
\hline D & 0.9485 & 0.935 & 0.9492 & 0.8917 & 0.8618 & 0.7491 \\
\hline M & 18.1675 & 14.5707 & 18.8268 & 9.0161 & 6.8768 & 3.7524 \\
\hline $\mathrm{H}$ & \multicolumn{2}{|c|}{0.6729} & \multicolumn{2}{|c|}{0.6286} & \multicolumn{2}{|c|}{0.5427} \\
\hline $\mathrm{J}$ & \multicolumn{2}{|c|}{0.6522} & \multicolumn{2}{|c|}{0.7193} & \multicolumn{2}{|c|}{0.7143} \\
\hline
\end{tabular}


Estimates of biodiversity indices based on RFLP data were assessed using the Species Prediction and Diversity Estimation software. Coverage estimates for these libraries were very high (99.7-98.0\%, Good's $C$ ), indicating that library size effectively reflects microbial diversity. The estimated sample coverage for rare species showed the same trend (90.9-98.9\%). Estimated $C V$ rare $=0.674$ in actinomycete clones signified moderate heterogeneity in species detection probabilities, but low heterogeneity in fungal clones $(C V$ rare $=0.275)$. ACE predicted 33.3, 41.7, and 17.4 OTUs for fungi, bacteria, and actinomycete libraries, respectively, while Chao1 predicted 33.2, 42.0, and 17.3, respectively (Table 2 ).

\begin{tabular}{|c|c|c|c|c|c|c|c|c|c|c|c|}
\hline \multirow[t]{3}{*}{ Libraries } & \multirow[t]{3}{*}{ No. of clones } & \multirow[t]{3}{*}{ No. of OTUs } & \multirow[t]{3}{*}{ C } & \multirow[t]{3}{*}{$C_{-}$rare } & \multirow[t]{3}{*}{$\mathrm{CV}_{-}$rare } & \multicolumn{6}{|c|}{ No. of predicted OTUs } \\
\hline & & & & & & \multicolumn{3}{|c|}{$\mathrm{ACE}$} & \multicolumn{3}{|c|}{ Chao1 } \\
\hline & & & & & & Mean & Lower & Upper & Mean & Lower & Upper \\
\hline Fungi & 526 & 46 & 0.997 & 0.989 & 0.275 & 33.3 & 33.0 & 36.9 & 33.2 & 33.0 & 36.5 \\
\hline Bacteria & 382 & 57 & 0.980 & 0.956 & 0.447 & 41.7 & 39.6 & 51.1 & 42.0 & 39.5 & 55.8 \\
\hline Actinomycetes & 168 & 21 & 0.980 & 0.909 & 0.674 & 17.4 & 15.4 & 30.4 & 17.3 & 15.3 & 34.0 \\
\hline
\end{tabular}

\section{DISCUSSION}

Direct evaluation of microbial diversity in the rhizosphere soils of plants will help to overcome limitations to continuous cropping (van Elsas et al., 2002). According to ecological principles, the relationships between ecosystem functioning and biodiversity can be demonstrated by the insurance hypothesis (Yachi and Loreau, 1999). The principle of the insurance hypothesis suggests that high diversity can safeguard communities from unstable environmental conditions by increasing the range of conditions in which the community as a whole can thrive (Yachi and Loreau, 1999), as well as benefits long-term attainment of the community (Boles et al., 2004).

In this study, we found that in both healthy and diseased cotton, considerable differences in diversity were observed, which could indicate microbial communities to be sampled for characterization. Using culture-independent molecular methods, we found that microbial diversity and evenness in rhizosphere soil of healthy cotton was higher than that of diseased plants. In fungal communities, Fusarium (OTU2 in Figure 2A, accession No. KC191744) clones in the healthy and diseased rhizosphere soil accounted for 13.23 and $5.58 \%$, respectively. Combined with the results of Zhang (2012), Fusarium species appeared to be the main pathogens of cotton in our study area. Similar results for bacterial communities were described by Zhang et al. (2011). For the actinomycetes, the number of OTUs in healthy rhizosphere soil was higher than that in the diseased, demonstrating there may be more species in the former. This may be because high species diversity is beneficial for protecting the ecological balance, although only 2 typical samples from 15 years of cotton continuous cropping were collected in this experiment.

Furthermore, the theory of niche has become the central idea in explaining natural communities. Several parameters define a niche, including niche metrics (Hanski, 1978), breadth (Levins, 1968), overlap (May and MacArthur, 1972), and dimensions (Harpole and Tilman, 2007). The theory of niche breadth can be used to explain the potential of acclimatization of 
species and populations (Levins, 1968), while niche overlap explains the concomitant or similarity (May and MacArthur, 1972). In our experiments, soil microbes, including fungi, bacteria, and actinomycetes, in healthy rhizosphere soil had wider niche breadth than that in diseased cotton, suggesting that microbial communities in healthy rhizosphere soils have strong adaptability to the environment. Furthermore, small niche overlap was observed between the different microbial communities belonging to the healthy and diseased rhizosphere soils, respectively.

Rhizosphere soils in the healthy cotton appear to be significant reservoirs of microbial biodiversity. The high diversity and the niche breadth of this healthy habitat make it intriguing to study microbial communities in continuous cropping ecosystems, which harbor a greater diversity of potential niches than diseased habitats. Although our efforts were only in the composition and diversity of microbial communities in rhizosphere soils between healthy and diseased cotton, further studies are needed to better understand the interactions among various microbes and how they influence beneficial microorganisms.

\section{ACKNOWLEDGMENTS}

We are grateful to $\mathrm{Xu}$ Aiguo and Tian Jiwang for sampling assistance. Research supported by the Natural Science Foundation of China (\#30960015) and the Natural Science Foundation of Jiangxi Province (\#20132BAB204024).

\section{REFERENCES}

Amann RI, Ludwig W and Schleifer KH (1995). Phylogenetic identification and in situ detection of individual microbial cells without cultivation. Microbiol. Rev. 59: 143-169.

Bäckman JSK, Hermansson A, Tebbe CC and Lindgren PE (2003). Liming induces growth of a diverse flora of ammoniaoxidising bacteria in acid spruce forest soil as determined by SSCP and DGGE. Soil Biol. Biochem. 35: 1337-1347.

Boles BR, Thoendel M and Singh PK (2004). Self-generated diversity produces "insurance effects" in biofilm communities. Proc. Natl. Acad. Sci. U. S. A. 101: 16630-16635.

Brežná B, Ženišová K, Chovanová K, Chebeňová V, et al. (2010). Evaluation of fungal and yeast diversity in Slovakian wine-related microbial communities. Antonie Van Leeuwenhoek 98: 519-529.

Chao A and Shen T (2008). User's Guide for Program SPADE (Species Prediction and Diversity Estimation). Updated August, 2007. Available at [spade.gti-ia.dsic.upv.es/manuals/spade_manual.pdf]. Accessed October 31, 2007.

Costa R, Götz M, Mrotzek N, Lottmann J, et al. (2006). Effects of site and plant species on rhizosphere community structure as revealed by molecular analysis of microbial guilds. FEMS Microbiol. Ecol. 56: 236-249.

DeLong EF (2002). Microbial population genomics and ecology. Curr. Opin. Microbiol. 5: 520-524.

Fouratt MA, Rhodes JS, Smithers CM, Love NG, et al. (2003). Application of temperature gradient gel electrophoresis to the characterization of a nitrifying bioaugmentation product. FEMS Microbiol. Ecol. 43: 277-286.

Giri B, Giang PH, Kumari R and Prasad R (2005). Microbial Diversity in Soils. In: Microorganisms in Soils: Roles in Genesis and Functions (Buscot F, ed.). Springer, Verlag, 19-55.

Hanski I (1978). Some comments on the measurement of niche metrics. Ecology 59: 168-174.

Harpole WS and Tilman D (2007). Grassland species loss resulting from reduced niche dimension. Nature 446: $791-793$.

Heuer H, Krsek M, Baker P, Smalla K, et al. (1997). Analysis of actinomycete communities by specific amplification of genes encoding 16S rRNA and gel-electrophoretic separation in denaturing gradients. Appl. Environ. Microbiol. 63: 3233-3241.

$\mathrm{Hu}$ YS, Wu K, Li CX and Jia XC (2007). Effect of continuous cropping of cucumber on soil microbial population II variation analysis based on DGGE approach. Sci. Agric. Sin. 40: 2267-2273.

Huang LN, Zhou H, Zhu S and Qu LH (2006). Phylogenetic diversity of bacteria in the leachate of a full-scale recirculating landfill. FEMS Microbiol. Ecol. 50: 175-183.

Hugenholtz P (2002). Exploring prokaryotic diversity in the genomic era. Genome Biol. 3: REVIEWS0003.

Kennedy A (1998). The Rhizosphere and Spermosphere. Principles and Applications of soil Microbiology. Prentice Hall, Upper Saddle River. 
Kowalchuk GA, Gerards S and Woldendorp JW (1997). Detection and characterization of fungal infections of Ammophila arenaria (marram grass) roots by denaturing gradient gel electrophoresis of specifically amplified 18s rDNA. Appl. Environ. Microbiol. 63: 3858-3865.

Levins R (1968). Evolution in Changing Environments: Some Theoretical Explorations. (MPB-2). Princeton University Press, Princeton.

Li CG, Li XM and Wang JG (2006). Effect of soybean continuous cropping on bulk and rhizosphere soil microbial community function. Acta Ecol. Sin. 26: 1144-1150.

May RM and MacArthur RH (1972). Niche overlap as a function of environmental variability. Proc. Natl. Acad. Sci. U. S. A. 69: 1109-1113.

Mintie AT, Heichen RS, Cromack K Jr, Myrold DD, et al. (2003). Ammonia-oxidizing bacteria along meadow-to-forest transects in the Oregon Cascade Mountains. Appl. Environ. Microbiol. 69: 3129-3136.

Mullis KB, Ferre F and Gibbs R (1994). The polymerase chain reaction (Nobel Lecture). Angew. Chem. Int. Ed. Engl. 33: 1209-1213.

Olsen GJ, Lane DJ, Giovannoni SJ, Pace NR, et al. (1986). Microbial ecology and evolution: a ribosomal RNA approach. Annu. Rev. Microbiol. 40: 337-365.

Pallant J (2007). SPSS Survival Manual: A Step by Step Guide to Data Analysis Using SPSS for Windows Version 15. Open University Press, Berkshire.

Pilon-Smits E (2005). Phytoremediation. Annu. Rev. Plant Biol. 56: 15-39.

Sambrook J, Russell DW, Janssen K and Argentine J (2001). Molecular Cloning: a Laboratory Manual on the Web. Cold Spring Harbor Laboratory, Cold Spring Harbor, New York.

Sipos R, Székely AJ, Palatinszky M, Révész S, et al. (2007). Effect of primer mismatch, annealing temperature and PCR cycle number on 16S rRNA gene-targetting bacterial community analysis. FEMS Microbiol. Ecol. 60: 341-350.

Stach JE, Maldonado LA, Ward AC, Goodfellow M, et al. (2003). New primers for the class Actinobacteria: application to marine and terrestrial environments. Environ. Microbiol. 5: 828-841.

Stockdale EA and Brookes PC (2006). Detection and quantification of the soil microbial biomass - impacts on the management of agricultural soils. J. Agric. Sci. 144: 285-302.

Tringe SG and Hugenholtz P (2008). A renaissance for the pioneering 16S rRNA gene. Curr. Opin. Microbiol. 11: 442446.

van Elsas JD, Garbeva P and Salles J (2002). Effects of agronomical measures on the microbial diversity of soils as related to the suppression of soil-borne plant pathogens. Biodegradation 13: 29-40.

Warnecke F, Luginbühl P, Ivanova N, Ghassemian M, et al. (2007). Metagenomic and functional analysis of hindgut microbiota of a wood-feeding higher termite. Nature 450: 560-565.

Whipps JM (2001). Microbial interactions and biocontrol in the rhizosphere. J. Exp. Bot. 52: 487-511.

White T, Bruns T, Lee S and Taylor J (1990). Amplification and Direct Sequencing of Fungal Ribosomal RNA Genes for Phylogenetics. PCR Protocols: A Guide to Methods and Applications. Academic Press, New York, 315-322.

Yachi S and Loreau M (1999). Biodiversity and ecosystem productivity in a fluctuating environment: the insurance hypothesis. Proc. Natl. Acad. Sci. U. S. A. 96: 1463-1468.

Zhang CL, Sun Q and Ye Q (2005). Obstacle effect of continuous cropping on Salvia miltiorrhiza growth. Acta Bot. Boreal.-Occid. Sin. 25: 1029-1034.

Zhang XJ (2012). Studies on the Occurrence Regularity of Cotton Fusurium wilt and its Control in Shajingzi Irrigation District in Xinjiang. Beijing Agricultural, Beijing, 3-79.

Zhang Y, Du BH, Jin ZG and Li ZH (2011). Analysis of bacterial communities in rhizosphere soil of healthy and diseased cotton (Gossypium sp.) at different plant growth stages. Plant Soil 339: 447-455.

Zheng LZ and Yu PP (1996). Annals of Regimental Farm No. 3, Agricultural Division No. 1, The Xinjiang Production and Construction Corps. Xinjiang Peoples Publishing House, Urumqi.

Zhou J, Bruns MA and Tiedje JM (1996). DNA recovery from soils of diverse composition. Appl. Environ. Microbiol. 62: 316-322. 